\title{
Low temperature fatigue properties of the joints of SMA490BW weathering resistant steel
}

\author{
Wu Yongshou ${ }^{1, a}$, Zhang Zhiyi ${ }^{1}$, Qi Weichuang ${ }^{1}$, Wu Xiangyang ${ }^{1}$, He Yongpan ${ }^{2}$, \\ Chen huil ${ }^{2, \mathrm{~b} *}$ \\ ${ }^{1}$ CRRC QINGDAO SIFANG Co., LTD. China, Qingdao. \\ ${ }^{2}$ Southwest Jiaotong University, School of materials science and engineering, China, Chengdu. \\ a wuyongshou2003@163.com, ${ }^{\mathrm{b}} \mathrm{xnrpt@163.com}$
}

Keywords: SMA490BW weathering resistant steel; low-temperautre fatigue properties; microstructures; mechanical properties at low temperature.

Abstract. Microstructures of SMA490BW weathering steel welded joints are investigated. Tensile tests, impact tests and bending tests of joints were carried out to investigate the mechanical properties from the test temperature of $0^{\circ} \mathrm{C}$ to $-40^{\circ} \mathrm{C}$. And the fatigue properties of jonits at $-40^{\circ} \mathrm{C}$ and $0^{\circ} \mathrm{C}$ are discussed in the article. Fracture surface of impact joints of different temperautre are observed. Well-formed welded joint has been obtained by MIG welding method. There are no cracks and other weld defects are found in the joints. In the temperature range of $0-40{ }^{\circ} \mathrm{C}$, all the tensile specimens are broken at the base metal, and the tensile strength increases with the decreasing temperature. Impact toughness of weld decreases with the decreasing temperature. Fracture mode of base material transforms into quasi-cleavage fracture by the dimple mode at $-40^{\circ} \mathrm{C}$. Cleavage fracture surface is observed of the weld at the temperature of $0^{\circ} \mathrm{C}$ and $-40^{\circ} \mathrm{C}$. Cracks and other surface defects are not found in the bending test of the weld at the temperature of $-40^{\circ} \mathrm{C}$.

\section{Introduction}

Weathering resistant steel are widely used in the manufature of the bogie of the high speed train. Bogie is the key compoment of the high-speed train in the normal operation, and the quality of welding joint directly affects the safety of railway vehicles [1-2]. The reaserch of wethering resistant steel concentrate on the corrosion behavior and the mechanical properties, however, the temperature of service of the high speed train is lower than $-37.3^{\circ} \mathrm{C}$. as a result, new chanllenge is required to the materials and the welding of the bogie of the high speed train. Lu [3] invetigated the mechanical properties and the fracture mechanism of the joints of S355 steel and Q345D steel at the low temperature. It is found that the fracture toughness property decreased with the decline of temperature, while the tensile strength increased with the decreasing of temperature. No significant elongation and notch sensitivity coefficient are observed. Mechannical properties and fatigue properties of the joints with manual welding and automatic welding of SMA490BW weathering resistant steel has been compared by Li [4], it is found that the mechanical properties with manual welding is better than the one with manual welding methods, and the fatigue properties are nearly the same with the two welding methods[5]. Tensile, impact and fatigue test were studied at low temperature, and it is found that the tensile strength improved with the decilne of the temperature. Impact energy decreased with the decreasing of testing temperature [6]. Recently there are hardly much reaserch about the mechanical properties at low temperature, as a result, SMA490BW steel has been joined by MAG welding, and the microstucture and mechanical properties of low temperature were investigated in this aricle.

\section{Experimental}

\section{Materials}

The base metal is SMA490BW steel with the size of $350 \mathrm{~mm} \times 150 \mathrm{~mm} \times 12 \mathrm{~mm}$, and JM-55 I Iwire with the diameter of $1.2 \mathrm{~mm}$ were used to weld SMA490BW steel. $80 \% \mathrm{Ar}$ and $20 \% \mathrm{CO} 2$ are used as 
the sheilding air, and the chemical compostion of the base metal and the wire is shown in Table.1. The mechanical properties of the base metal and the wire are shown in Table.2.

Table.1 Chemical composition of base metal and wire

\begin{tabular}{ccccccccc}
\hline Elments & $\mathrm{C}$ & $\mathrm{Si}$ & $\mathrm{Mn}$ & $\mathrm{S}$ & $\mathrm{P}$ & $\mathrm{Cu}$ & $\mathrm{Cr}$ & $\mathrm{Ni}$ \\
\hline SMA490BW & $\leq 0.18$ & $\begin{array}{c}0.15 \sim 0.6 \\
5\end{array}$ & $\leq 1.40$ & $\leq 0.035$ & $\leq 0.035$ & $\begin{array}{c}0.30 \sim 0.5 \\
0\end{array}$ & $0.45-0.75$ & $\begin{array}{c}0.05 \sim 0.3 \\
0\end{array}$ \\
\hline JM-55II & 0.08 & 0.545 & 1.40 & 0.008 & 0.012 & 0.25 & 0.65 & 0.35 \\
\hline \multicolumn{7}{c}{ Table.2 Mechanical properties of base metal and wire } & & \\
\hline Mechanical & Tensile strength & Yeild strength & Elongation & Impact energy \\
properties & /MPa & /MPa & / & (-40 $) / \mathrm{J}$ \\
\hline SMA490BW & $490 \sim 610$ & $\geq 365$ & $\geq 15$ & $\geq 27$ \\
\hline JM-55II & $\geq 625$ & $\geq 520$ & $\geq 26$ & $\geq 80$ \\
\hline
\end{tabular}

\section{Methods}

The size of the plate welded with single wire welding is $350 \times 150 \times 12 \mathrm{~mm}$, and the groove preparation is shown in Fig.1. The shielding gas is $80 \% \mathrm{Ar}$ and $20 \% \mathrm{CO}_{2}$, and the welding process is shown in Table.2. The size of the plate welded with double wire MAG welding is $350 \times 150 \times 12 \mathrm{~mm}$. The groove preparation and the shielding gas are same as the single wire welding process, which is shown in Table.3. The microstructure of joints welded with single wire welding process and double wire welding is shown in Fig.2a and Fig.2b. Multi-layer MAG welding method is used to weld SMA490BW weathering steel, and butt joint with the groove form using V groove with a blunt edge, as shown in figure 1 . The back welding current is 120-140 A, and filling and covering the welding current is 250-280 A, and the welding voltage is $23-25 \mathrm{v}$. Microstructure of the joint is analyzed by Zeiss stereo microscope. DNS300 electronic universaltesting machine is used to test the tensile strength, bending properties and impact properties between the temperature ranges of $-40^{\circ} \mathrm{C}$ to $0^{\circ} \mathrm{C}$. As the tensile test is carried on the machine, the moving velocity of the machine is $3 \mathrm{~mm} / \mathrm{min}$. Four side-bending tests are carried on of the joints. The impact tests are carried on in the JBN-300 impact testing machine. Liquid nitrogen was used to cool the sample to the testing temperature, and holding for $30 \mathrm{~min}$ before the test.

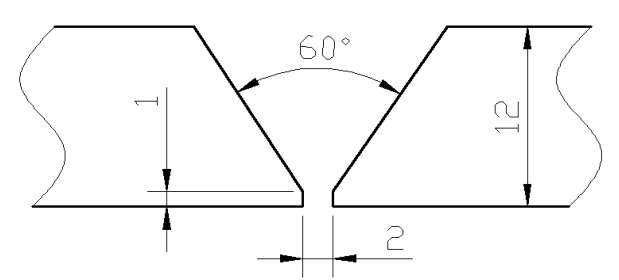

Fig.1. Groove type of welded joints

\section{Results and discussion}

\section{Microstructure and hardness}

Microstructure of SMA490BW steel joints is shown in figure 2, a sound weld is obtained and no cracks and significant defects are observed in the weld. Columnar crystal is oberbed growing to the weld pool. The columnar crystal grew approximately perpendicular to the weld molten pool boundary as the typical epitaxial solidification microstructure. The distribution of hardness of the joints is shown in Fig.3. It can be seen from Fig.3, the hardness of the base metal is about $160 \mathrm{Hv}$, and the hardness of the joint peaked at $210 \mathrm{Hv}$ at the HAZ zone. The hardness of the weld is about $160 \mathrm{Hv}$. 


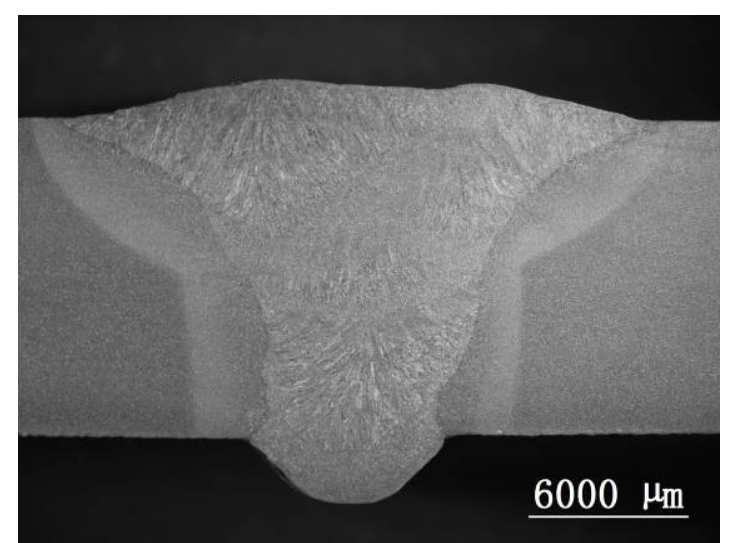

Fig.2. Microstructure of the joints

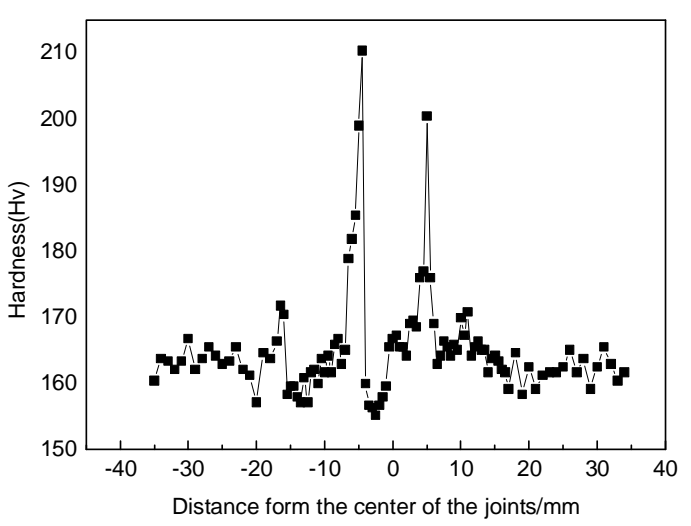

Fig.3. Distribution of hardness of the joints

\section{Low temperature tensile strength}

Joints of the tensile samples were all broke in the base metal at the temperaure of the range of $-40^{\circ} \mathrm{C} \sim 0^{\circ} \mathrm{C}$. The results of the tensile strength were shown in Fig.4, it can be seen that with the temperaure decreasing, the tensile strength and the yield strength increased. The tensile strength and yield strength at the temperature of $-40^{\circ} \mathrm{C}$ increased $32 \mathrm{MPa}$ and $26 \mathrm{MPa}$ than the ones that of at $0^{\circ} \mathrm{C}$, respectively. It has been considered that the reduction of temperature contributes to the grain arrangement of material, which resulting the deformation resistance material increases, and thus improved the tensile strength and yield strength of material [3]. Some reserchers pointed that dislocation was hindered by solid solution atoms (carbon, nitrogen, etc.) at low temperature, which made the dislocation slip resistance increased, and improved the strength of materials [4].
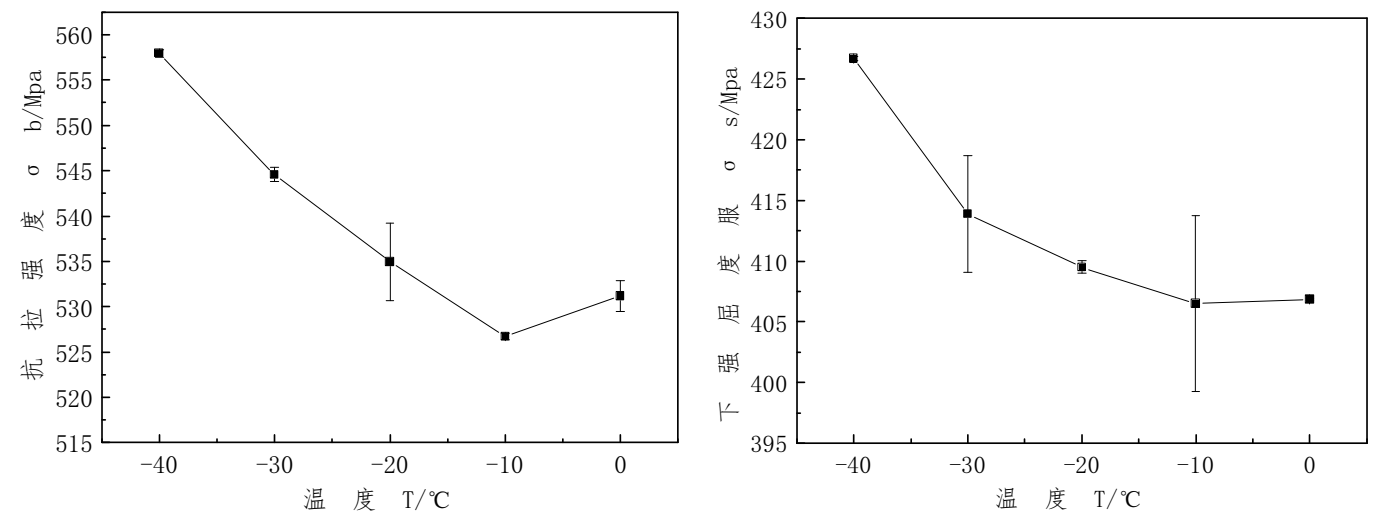

Fig.4 Relationship between the tensile strength and yield strength and temperature of joints:

(a) tensile strength (b) yield strength

\section{Low temperature bending}

Fig.5 shows the bending sample of the joints of SMA490BW weathering steel at the temperature of $0^{\circ} \mathrm{C}$ and $40^{\circ} \mathrm{C}$. It can be seen from Fig.5, due to the strong plastic deformation, the shape of weld in the sample after bending was more visible. And there were no obvious welding defects such as inclusions observed in the weld at both $0^{\circ} \mathrm{C}$ and $40^{\circ} \mathrm{C}$. Although low temperature decreased the plasticity of the joints, but the adverse effects did not response to the bending results. It shows that quality of the welding is good, which had enough resistance to bending deformation ability. 


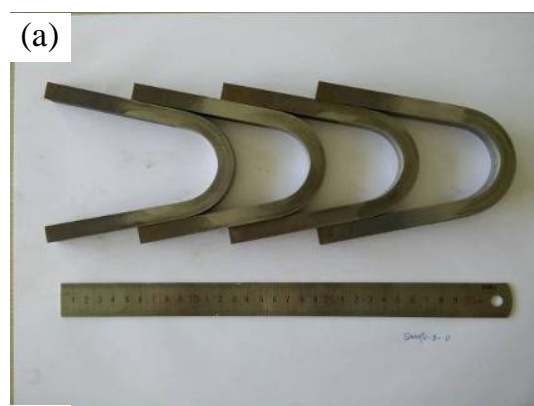

(c)

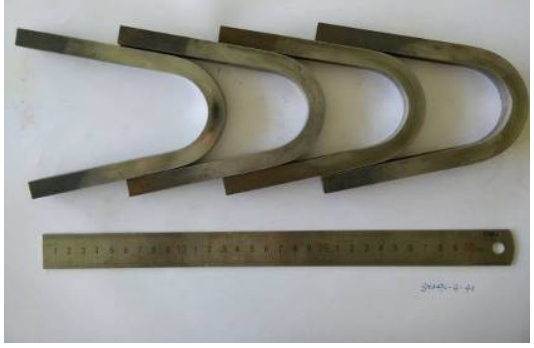

(b)

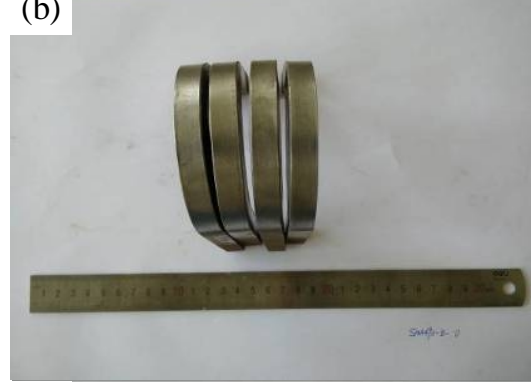

(d)

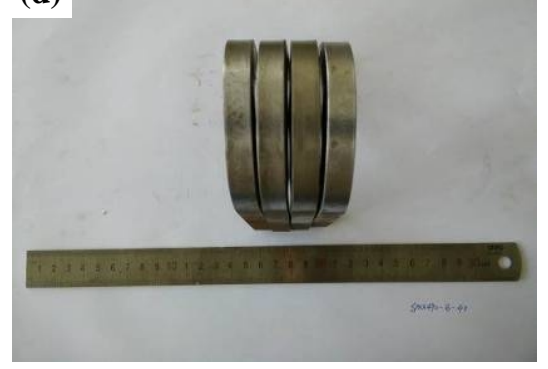

Fig.5 Bent sample with different temperature of the joints.

(a) cross section of $0^{\circ} \mathrm{C}$; (b) back section of $0^{\circ} \mathrm{C}$; (c) cross section of $-40^{\circ} \mathrm{C}$; (d) back section of $-40^{\circ} \mathrm{C}$.

\section{Low temperature impact properties}

The impact tests of the weld were carried on at the temperature range of $0^{\circ} \mathrm{C} \sim-40^{\circ} \mathrm{C}$, the test samples were shown Fig.6. Fig.7 shows the relationship between impact energy and temperature. It can be seen from Fig.7, with the temperature decreasing, the impact properties increased before $-10^{\circ} \mathrm{C}$ and peaked at $126 \mathrm{~J}$. And then with the temperature decreasing, the impact properties declined sharply, the impact energy of the one at the temperature of $-40^{\circ} \mathrm{C}$ decreased $64 \%$ of the one at the temperature of $0^{\circ} \mathrm{C}$.

Fig.8 shows the fracture surface of the impact samples, cleavage fracture patterns surface were observed at the joints with the impact test temperature of $0^{\circ} \mathrm{C}$ and $40^{\circ} \mathrm{C}$. River pattern flew from small plane boundary spreading outward, and the source of crack can be found in the opposite direction along the river pattern. Brittle fracture surface of the weld are the mainly characteristics, which contributes to the poor impact toughness of weld.

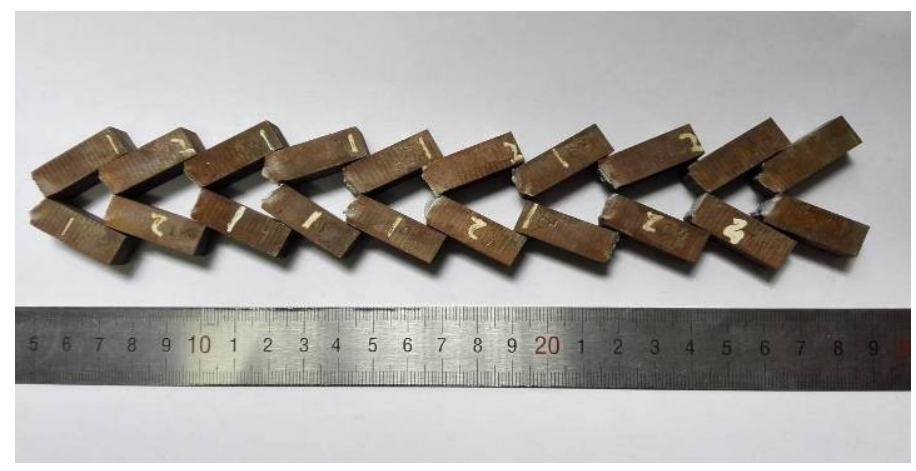

Fig.6. Impact samples with different test temperature 


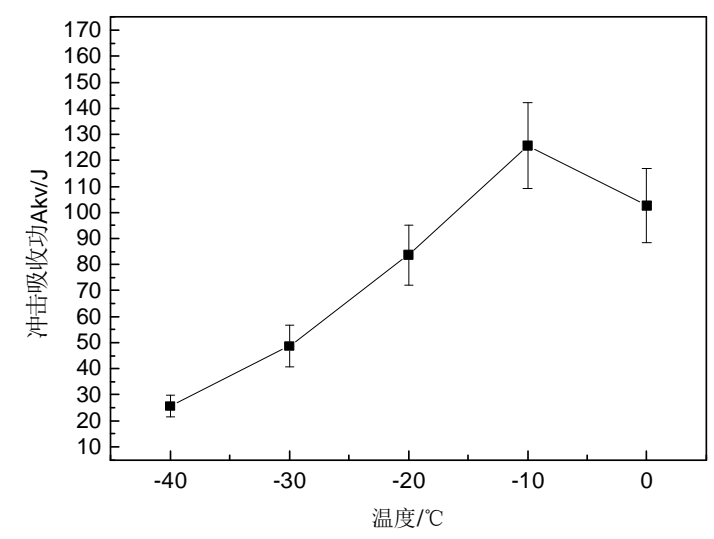

Fig.7 Relationship between the impact energy and temperature of joints.

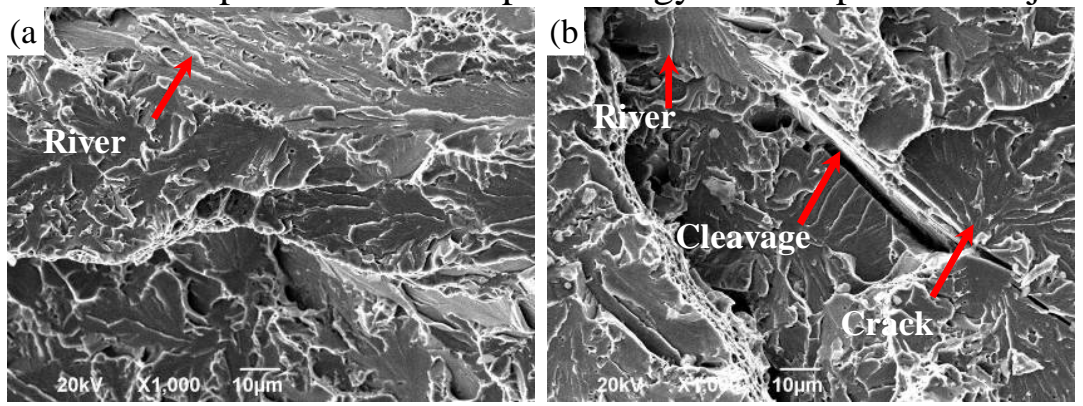

Fig.8 The fracture surface of impact sample of the joints: (a) at $0^{\circ} \mathrm{C}$; (b) weld at $-40^{\circ} \mathrm{C}$.

\section{Low temperature fatigue strength}

Fatigue strength of SMA490BW steel joints were carried on the fatigue testing machine with insulation box, and the stress ratio is 0 . The fatigue strength of joints with different testing temperature was shown in Fig.9. The first stress class level was selected according to the results of the tensile stress. Fatigue test of eight level stresses were conducted, and the amount of data were increased at the close stress level to the limit to ensure the accuracy of the fatigue limit. S-N curves are fitting according to each stress level fatigue life, and the fitting of the fatigue limit is $370 \mathrm{MPa}$ at the testing temperature of $0^{\circ} \mathrm{C}$. And with the temperature decreaed to $-40^{\circ} \mathrm{C}$, the fatigue curves are shown in Fig. $9 \mathrm{~b}$, it can be resulted that the fatigue strength improved to $390 \mathrm{MPa}$.
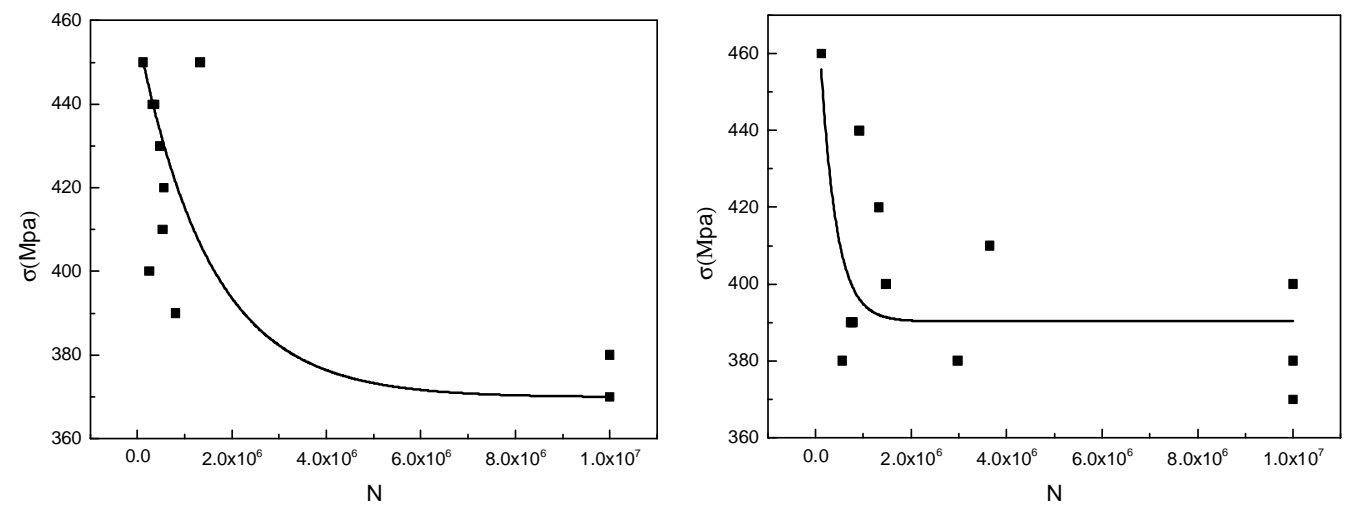

Fig.9 The fatigue strength with different testing temperature. (a) $0^{\circ} \mathrm{C},\left(\right.$ b) $-40^{\circ} \mathrm{C}$.

The fatigue fracture surface was shown in Fig.10. There are no significant defect are observed in the fatigue source in Fig.10 (a), and typicle fatigue striations are found in Fig.10 (b). There are some cracks distributed between the fatique striations, which are considered to be some brittle characters of materials. Fig.10 (c) shows the fatigue final rupture region, and there are some flat dimples in the fracture surface, which implies there is some extent toughness even at the temperature of $-40^{\circ} \mathrm{C}$. 

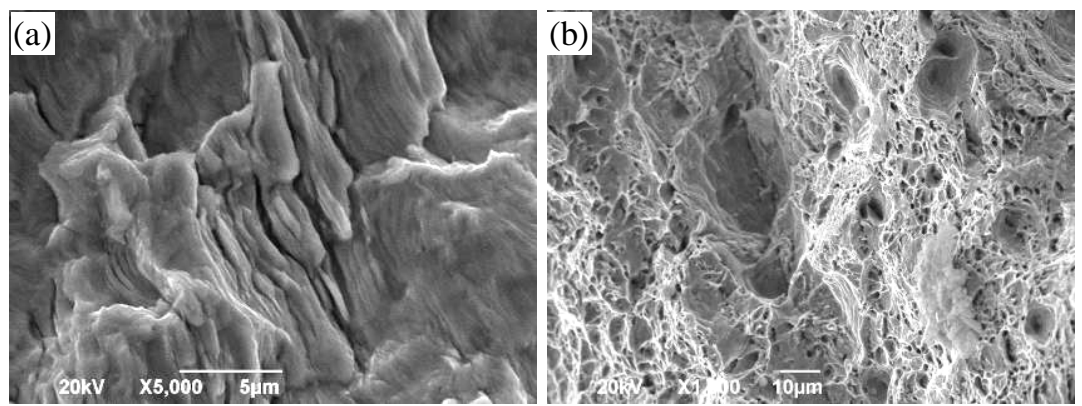

Fig.10 Fracture surface of fatigue samples at $-40^{\circ} \mathrm{C}$.

(a) fatigue sourse, (b) fatigue striations, (c) fatigue final rupture region

\section{Conclusions}

(1) Multi-layer MAG welding was used to obtain a sound weld without cracks and significant defects in the weld. M type distribution of hardness of the joint is observed, and peaked at $210 \mathrm{Hv}$ at the HAZ zone, and the hardness of the base metal and the weld are about $160 \mathrm{Hv}$.

(2) With the temperaure decreasing, the tensile strength and the yield strength increased. The tensile strength and yield strength at the temperature of $-40^{\circ} \mathrm{C}$ increased $32 \mathrm{MPa}$ and $26 \mathrm{MPa}$ than the ones that of at $0^{\circ} \mathrm{C}$, respectively.

(3) With the temperature decreasing, the impact properties increased and peaked at $126 \mathrm{~J}$ at $-10^{\circ} \mathrm{C}$. And then with the temperature decreasing, the impact energy of the one at the temperature of $-40^{\circ} \mathrm{C}$ decreased $64 \%$ of the one at the temperature of $0^{\circ} \mathrm{C}$. There are no obvious welding defects observed in the weld at both $0^{\circ} \mathrm{C}$ and $40^{\circ} \mathrm{C}$

(4) S-N curves are fitting according to each stress level fatigue life, and the fitting of the fatigue limit is $370 \mathrm{MPa}$ at the testing temperature of $0^{\circ} \mathrm{C}$. And with the temperature decreaed to $-40^{\circ} \mathrm{C}$, the fatigue curves are shown in Fig.9b, it can be resulted that the fatigue strength improved to 390MPa.

\section{References}

[1] Jiang Xishan, Zhao Han. Quick manual of microscopic fracture of steel[M].Beijing: China Machine Press, 2010. (in chinese).

[2] Bai Zhifan, Li Guizhong, Wang Chao. Journal of Jilin University[J]. 2012, 42(1): 208-211 (in chinese).

[3] Lu Lin, Li Zhoubo. Low temperature engineering[J]. 2012,189(5):55-57. (in chinese).

[4] Li Xiaona. Electric welding machine[J], 2015, 45(6): 81-85. (in chinese).

[5] Wu xiangyang, Zhang Zhiyi. Hot Working Technology[J]. 2015, 44(19): 29-31. (in chinese).

[6] Parkes D,Westerbaan D,Nayak S.S,et al.Materials and Design[J],56(2014):193-199.

[7] Liu Chunting. Mechanical properties of materials[M]. Beijing: Chemical Industry Press, 2009. (in chinese).

[8] Wang jing. Inner Mongol University of Technology[D], 2009. (in chinese). 